\title{
A SYSTEMATIC REVIEW OF TUMOR NECROSIS FACTOR- $\alpha$ IN POST-TRAUMATIC STRESS DISORDER: EVIDENCE FROM HUMAN AND ANIMAL STUDIES
}

\author{
Serkan Hussein*,1,2, Bethan Dalton*,1, Gerd D. Willmund ${ }^{3}$, \\ Mohammad A. A. Ibrahim ${ }^{4} \&$ Hubertus Himmerich ${ }^{1}$ \\ ${ }^{1}$ Department of Psychological Medicine, King's College London, London, UK \\ ${ }^{2}$ Faculty of Life Sciences and Medicine, King's College London, UK \\ ${ }^{3}$ Department of Psychiatry, Psychotherapy and Psychotraumatology, Bundeswehr Hospital, Berlin, Germany \\ ${ }^{4}$ Department of Immunological Medicine and Allergy, King's Health Partners, King's College Hospital, London, UK \\ *Serkan Hussein and Bethan Dalton contributed equally to this article
}

received: 1.6.2017;

revised: 5.10.2017;

accepted: 25.10 .2017

\section{SUMMARY}

Background: Growing evidence suggests a pathophysiological role of cytokines in post-traumatic stress disorder (PTSD). Tumor necrosis factor (TNF)- $\alpha$ is a key cytokine. Therefore, we performed a systematic review to examine the findings regarding TNF- $\alpha$ derived from both animal and human studies of PTSD.

Methods: Using PRISMA guidelines, we reviewed relevant articles in PubMed from inception until $11^{\text {th }}$ April 2017. Human studies that reported group comparisons and/or longitudinal investigations of TNF- $\alpha$ production/concentration were included. Research reporting on TNF- $\alpha$ levels in animal models of PTSD were also included.

Results: Twenty-seven articles were identified. Data from human cross-sectional studies suggests that plasma/serum levels of TNF- $\alpha$ are elevated in those with PTSD, as compared to healthy controls. Longitudinal assessments of TNF- $\alpha$ are limited and data are mixed. Limited data from animal studies suggest an increased TNF- $\alpha$ production in the hippocampus of rats following stress, which can be reversed by immunomodulatory drugs.

Conclusions: Our findings suggest TNF- $\alpha$ may be a potential biomarker and treatment target for PTSD. Findings need to be considered in light of heterogeneous methods for measurement and analysis of TNF- $\alpha$ concentration. Longitudinal research is needed to understand the role of TNF- $\alpha$ in the development and/or maintenance of PTSD.

Key words: cytokines - tumor necrosis factor (TNF)-alpha - Post-traumatic stress disorder - biomarker - immunomodulatory drugs

\section{INTRODUCTION}

Post-traumatic stress disorder (PTSD) is a mental disorder, which may develop following an exposure to traumatic events, such as war, catastrophic accidents, and instances of violence. According to the International Classification of Diseases (ICD)-10, the specific criteria for diagnosis include (i) the exposure to a stressful event or situation of exceptionally threatening or catastrophic nature; (ii) a persistent remembering or "reliving" of the stressor, and (iii) avoidance of circumstances resembling or associated with the stressor. In addition, either the inability to recall important aspects of the period of exposure to the stressor, or persistent symptoms of increased psychological sensitivity and arousal need to be present (WHO 1992). To make the diagnosis, these symptoms must persist for more than a month after the occurrence of a traumatic event (WHO 1992). Similar criteria are used in the Diagnostic and Statistical Manual of Mental Disorders (DSM)-5 to diagnose PTSD, namely the exposure to a traumatic event, in addition to having symptoms from each of the four symptom clusters: avoidance, intrusion, negative alterations in cognitions and mood, and alterations in arousal and reactivity. Furthermore, the functioning of a patient must be impaired and their symptoms should not be attributable to substance abuse or a co-occurring medical condition (APA 2013). To establish the diagnosis of PTSD, several clinical interviews and questionnaires are available, most of which are based on DSM-IV or DSM-5 criteria. Examples of diagnostic instruments related to the presented topic are the ClinicianAdministered PTSD Scale (CAPS; Blake et al. 1995), the PTSD Checklist (PCL; Blanchard et al. 1996; a civilian and military version are also available, PCL-C and PCL-M respectively, Weathers et al. 2013), the Structured Clinical Interview for DSM Disorders (SCID-I; Spitzer et al. 1992, Ventura et al. 1998), the Los Angeles Symptom Checklist (LASC; King et al. 1995), the Short Post-Traumatic Stress Disorder Rating Interview (SPRINT; Connor \& Davidson 2001) and the Posttraumatic Diagnostic Scale (PDS; Foa et al. 1997, Sheeran \& Zimmerman 2002).

Traumatic exposure itself is not the only causal factor for PTSD. The type and duration of trauma, psychological factors like personality characteristics, gender, and biological factors all seem to play a significant role in PTSD aetiology (Yehuda et al. 1995, Breslau et al. 1997, Frans et al. 2005). Several mechanisms have been implicated in the pathophysiology of PTSD including 
genetics, epigenetics, and neurobiological systems (Pitman et al. 2012, Bailey et al. 2013, Ryan et al. 2016). Recently, PTSD research has focused on immune mechanisms, for example, peripheral blood mononuclear cells (PBMCs) and cytokines, such as tumor necrosis factor-alpha (TNF- $\alpha$; Andrews \& Neises 2012). TNF- $\alpha$ is an inflammatory, pleiotropic cytokine mainly produced by macrophages to aid immune cell regulation (Lebrec et al. 2015). Apart from its key immune-regulatory role, it has been associated with several psychiatric disorders including depression, schizophrenia, and Alzheimer's disease (Himmerich et al. 2008, Lorz et al. 2009, Schmidt et al. 2014, Balõtšev et al. 2016, Decourt et al. 2017). Furthermore, research has suggested proinflammatory markers, such as TNF- $\alpha$, are potentially involved in the development of PTSD (von Känel et al. 2007). TNF- $\alpha$ acts via two types of TNF receptors (TNF-R), TNF-R p55 and TNF-R p75. TNF- $\alpha$ is produced from peripheral immune cells and also in the central nervous system, having receptors on the surface of neurons and glial cells (Idriss \& Naismith 2000). Evidence suggests that the blood-brain barrier is permeable to peripherally produced cytokines, including TNF- $\alpha$. Thus, TNF- $\alpha$ can influence brain physiology by stimulating the hypothalamic-pituitary-adrenocortical (HPA) axis, activating monoamine reuptake and decreasing production of serotonin, due to the increased activity of indolamine-2,3-dioxygenase (Lichtblau et al. 2013).

Growing evidence suggests a pathophysiological role of pro-inflammatory cytokines in PTSD. As TNF- $\alpha$ is a key cytokine of the immune response (Lebrec et al. 2015), for which blocking drugs are available, we sought to carry out this review of research investigating TNF- $\alpha$ concentrations and/or production in human and animal studies of PTSD. The purpose of this systematic review is to summarise the evidence regarding the role of TNF- $\alpha$ in PTSD, and to assess its potential as a biomarker for PTSD and its treatment, in addition to assessing it as a potential future drug target. Specifically, we aim to (i) determine whether TNF- $\alpha$ concentration/production differs between those with and without PTSD; (ii) assess whether TNF- $\alpha$ concentrations change over time and/or in response to treatment; and (iii) explore the role of TNF- $\alpha$ in animal models of PTSD.

\section{METHODS}

This systematic review was conducted following the recommendations outlined in the PRISMA guidelines (Moher et al. 2009).

\section{Selection Criteria}

Studies of any design that assessed TNF- $\alpha$ production in-vitro or TNF- $\alpha$ concentration in the serum, plasma, or cerebrospinal fluid (in-vivo) of individuals with PTSD were eligible for inclusion. Studies were included if they reported a group and/or longitudinal comparison of TNF- $\alpha$ concentration/production. Publications reporting on the measurement of TNF- $\alpha$, the TNF- $\alpha$ protein or its messenger ribonucleic acid (mRNA) in animal models of PTSD were also included.

Studies were excluded if: (i) they focused on life difficulties or trauma rather than PTSD as defined by ICD-10 and DSM-5; (ii) they reported genetic data only; (iii) they measured TNF receptors only; (iv) they were investigating glucocorticoid receptor (GR) sensitivity only; or (v) they did not report a group and/or longitudinal comparison of TNF- $\alpha$ concentration/ production. Review articles, meta-analyses, conference proceedings/abstracts, editorials, letters, book chapters, and unpublished theses were also not included.

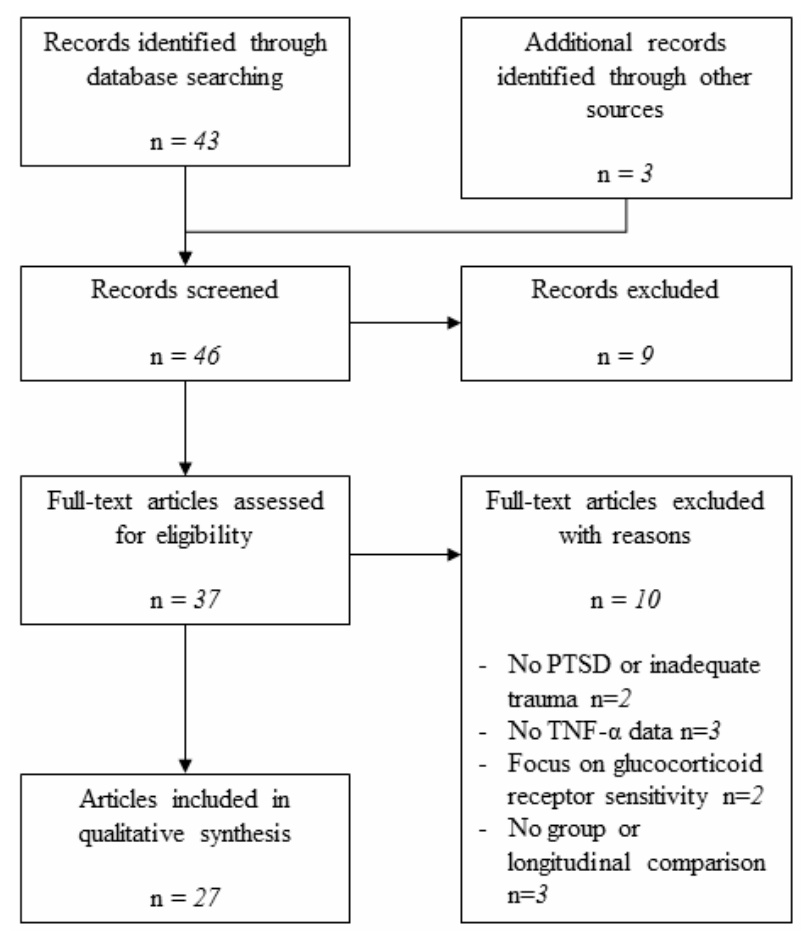

Figure 1. An overview of the literature search

\section{Search Strategy}

Pubmed was searched from inception until the $11^{\text {th }}$ April 2017 using the following key search terms: (("post-traumatic stress disorder"[Title/Abstract]) OR ("PTSD"[Title/Abstract])) AND (("tumor necrosis factor-alpha"[Title/Abstract]) OR ("tumor necrosis factor"[Title/Abstract]) OR ("TNF-alpha"[Title/Abstract]) OR ("TNF"[Title/Abstract]))

This search was supplemented by internet searches and hand searches of reference lists of included papers and potentially relevant reviews. Citation tracking in Google Scholar was also performed. Identified articles had their titles and abstracts screened according to the pre-specified eligibility criteria. The eligible articles were further reviewed in full text. The articles were subsequently categorised into animal and human studies and then further divided according to their study design. An overview of the literature search is shown in Figure 1. 


\section{Data Extraction}

The data from all included studies was extracted into an electronic summary table by the first author (SM), which was then checked by another author (BD). Information collected related to the sample characteristics, study design, and relevant findings.

\section{RESULTS}

\section{Characteristics of included studies}

A total of 27 articles were eligible for inclusion in this review. We identified three articles that used animal models of PTSD to assess TNF- $\alpha$ and 24 human studies (including data from a total of 1865 participants). The human studies were further categorized into articles with cross-sectional data using in vivo methods $(n=19$; including studies measuring serum or plasma concentrations of TNF- $\alpha$ ), articles with cross-sectional data on TNF- $\alpha$ production in-vitro $(\mathrm{n}=5)$, or articles with longitudinal data $(n=3)$, two of which considered the effect of treatment interventions on TNF- $\alpha$ concentrations. One of the included studies reported both cross-sectional and longitudinal data (Jergović et al. 2015) and another study provided data on in-vivo and in-vitro measurements of TNF- $\alpha$ (Gola et al. 2013).

\section{Assessment of PTSD symptoms}

Various questionnaires were used for assessment of PTSD symptoms in the included studies. Most studies used the CAPS (e.g. von Känel et al. 2007, Hammad et al. 2012, Gola et al. 2013, Lindqvist et al. 2014, Bersani et al. 2016, Lindqvist et al. 2017, Bruenig et al. 2017). However, other questionnaires, such as the PCL-M (Devoto et al. 2016), the PCL-C (Chen et al.
2014), the SCID-I (Bersani et al. 2016; Lindqvist et al. 2017), the PDS (Himmerich et al. 2015), and the LASC (Jergović et al. 2015), were also used. Some of the studies established the diagnosis clinically based on ICD-10 (Oganesyan et al. 2009) or DSM-IV criteria (Guo et al. 2012).

\section{Study findings: Animal Studies}

All included animal studies used animal models with male Sprague-Dawley rats. Two of the studies measured TNF- $\alpha$ levels (Levkovitz et al. 2015, Liu et al. 2016) and one assessed TNF- $\alpha$ mRNA (Lee et al. 2016) in the hippocampus of stressed rats. The results of these studies are presented in Table 1. Lee et al. (2016) induced anxiety using a single prolonged stress (SPS) procedure and found elevated TNF- $\alpha$ levels in the hippocampus of stressed rats, as compared to nonstressed rats. In contrast, stressed rats who received ibuprofen did not display elevated TNF- $\alpha$ expression; these levels did not significantly differ from nonstressed rats. In rats exposed to the predator scent stress (PSS) paradigm, Levkovitz et al. (2015) also found elevated TNF- $\alpha$ levels in the hippocampus, compared to rats not exposed to stress. In addition, in PSS-exposed rats treated with minocycline (a drug with anti-inflammatory capacities), normalised hippocampal TNF- $\alpha$ concentrations were observed. Furthermore, in both of these studies, treatment with medication resulted in a reduction in anxiety-like behaviours (as measured by the elevated plus maze test) to levels observed in non-stressed rats. Conversely, Liu et al. (2016) did not find any difference in TNF- $\alpha$ levels in the hippocampus of rats after SPS compared to nonstressed rats.

Table 1. Summary of animal studies investigating the relationship between TNF- $\alpha$ and PTSD

\begin{tabular}{|c|c|c|c|c|c|}
\hline Author & Animals & $\begin{array}{l}\text { PTSD } \\
\text { Model }\end{array}$ & $\begin{array}{l}\text { Measurement } \\
\text { of TNF- } \alpha\end{array}$ & $\begin{array}{c}\text { Findings regarding } \\
\text { TNF- } \alpha\end{array}$ & Additional findings/comments \\
\hline $\begin{array}{l}\text { Lee } \\
\text { et al. } 2016\end{array}$ & $\begin{array}{l}\text { Adult male } \\
\text { Sprague- } \\
\text { Dawley rats }\end{array}$ & SPS & $\begin{array}{l}\text { Hippocampal } \\
\text { mRNA } \\
\text { expression } \\
\text { levels; Reverse } \\
\text { transcription- } \\
\text { polymerase } \\
\text { chain reaction }\end{array}$ & SPS $>$ control & $\begin{array}{l}\text { Group treated with ibuprofen }(40 \mathrm{mg} / \mathrm{kg} \text { body } \\
\text { weight): } \\
\text { TNF- } \alpha \text { - SPS + ibuprofen = control; SPS + } \\
\text { ibuprofen }<\text { SPS } \\
\text { Anxiety index in elevated plus maze test }- \text { SPS } \\
>\text { SPS + ibuprofen; SPS + ibuprofen = control }\end{array}$ \\
\hline $\begin{array}{l}\text { Levkowitz } \\
\text { et al. } 2015\end{array}$ & $\begin{array}{l}\text { Male Sprague- } \\
\text { Dawley rats } \\
(n=99)\end{array}$ & PSS & $\begin{array}{l}\text { Hippocampal } \\
\text { protein levels; } \\
\text { Multiplexed } \\
\text { ELISA }\end{array}$ & PSS $>$ control & $\begin{array}{l}\text { In frontal cortex \& hypothalamus: TNF- } \alpha \text { - PSS } \\
=\text { control } \\
\text { Group treated with minocycline: } \\
\text { TNF- } \alpha \text { - PSS }>\text { PSS + minocycline } \\
\text { IL-1 } \alpha \text {, IL-6 - PSS > control; PSS }>\text { PSS + } \\
\text { minocycline } \\
\text { Anxiety-like behaviours (time spent in open } \\
\text { arms and entries) in elevated plus maze test - } \\
\text { PSS }>\text { control; PSS }>\text { PSS + minocycline; PSS } \\
+ \text { minocycline }=\text { control }\end{array}$ \\
\hline $\begin{array}{l}\text { Liu } \\
\text { et al. } 2016\end{array}$ & $\begin{array}{l}\text { Adult male } \\
\text { Sprague-Daw- } \\
\text { ley rats }(n=128)\end{array}$ & SPS & $\begin{array}{l}\text { Hippocampal } \\
\text { expressions; } \\
\text { ELISA }\end{array}$ & $\mathrm{SPS}=$ control & $\begin{array}{l}\text { IL-6 - SPS > control } \\
\text { IL- } 1 \beta, \text { IL-10 - SPS = control }\end{array}$ \\
\hline
\end{tabular}

TNF- $\alpha$ = tumor necrosis factor - alpha; SPS = single prolonged stress; mRNA = messenger ribonucleic acid; PSS = predator scent stress;

ELISA = enzyme-linked immunosorbent assays; $\mathrm{mg}=$ milligram; $\mathrm{kg}=$ kilogram; $\mathrm{IL}=$ interleukin 
Table 2. Human cross-sectional studies assessing plasma or serum concentrations of TNF- $\alpha$ in-vivo in individuals with and without PTSD

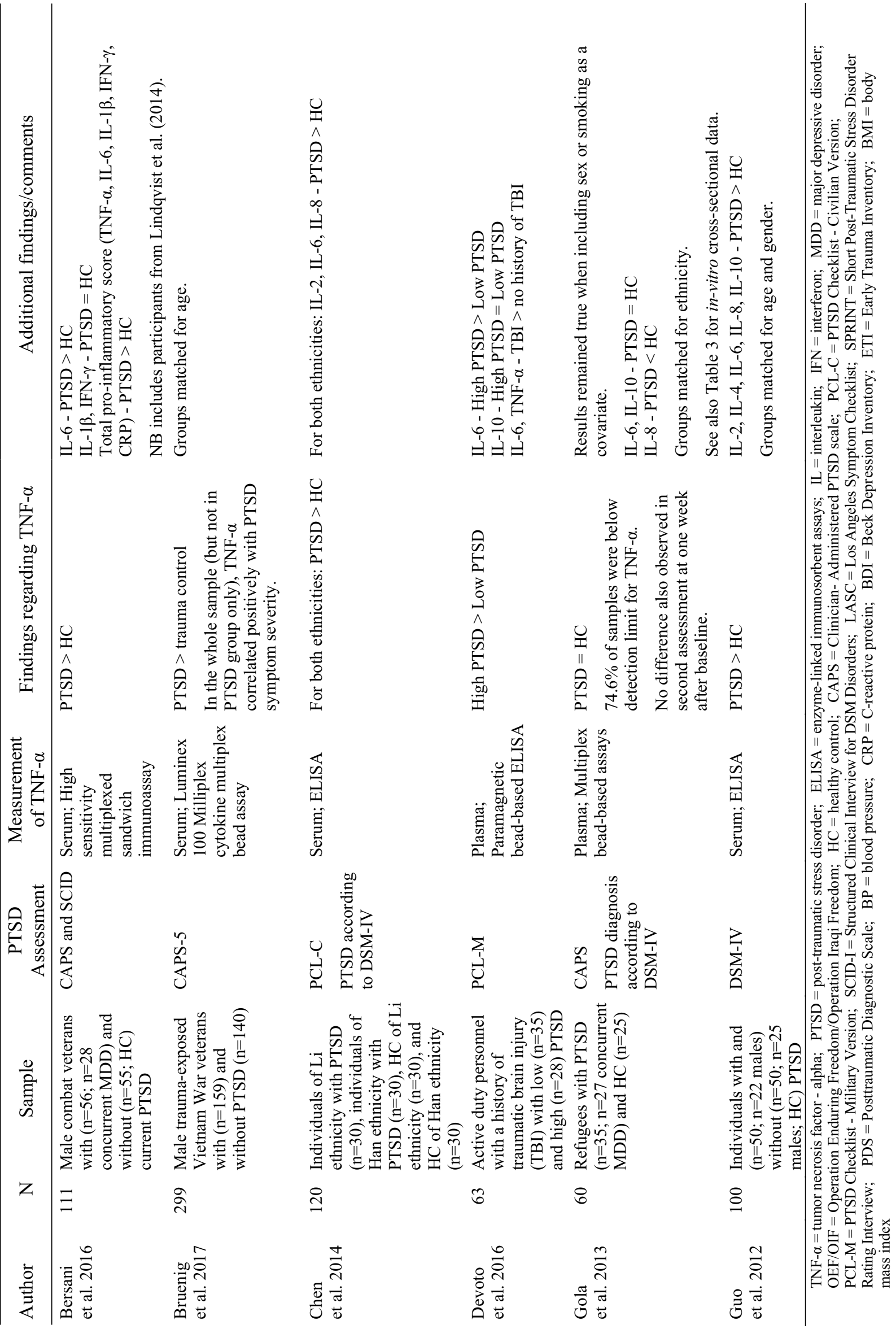


Table 2. Continues

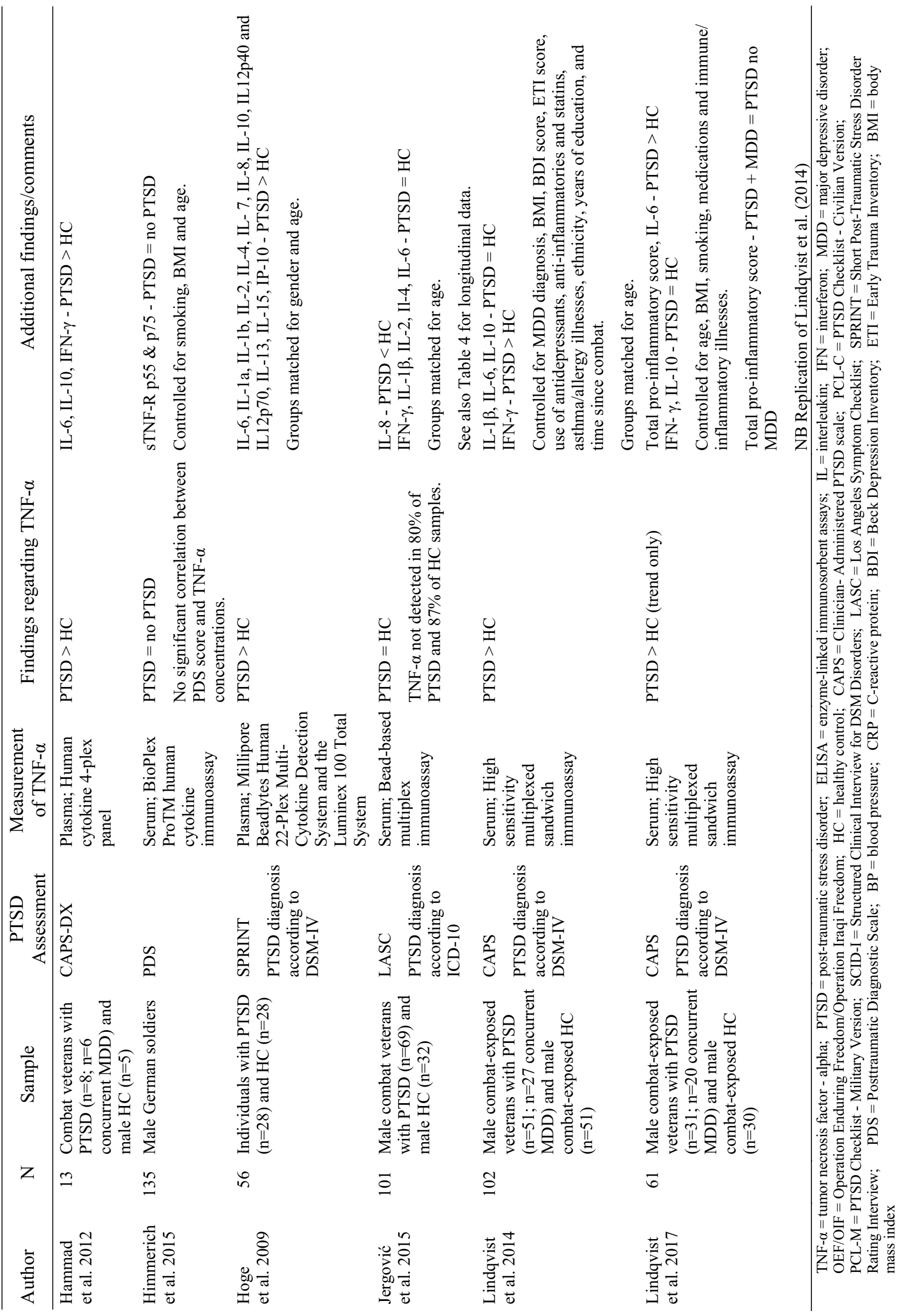


Table 2. Continues

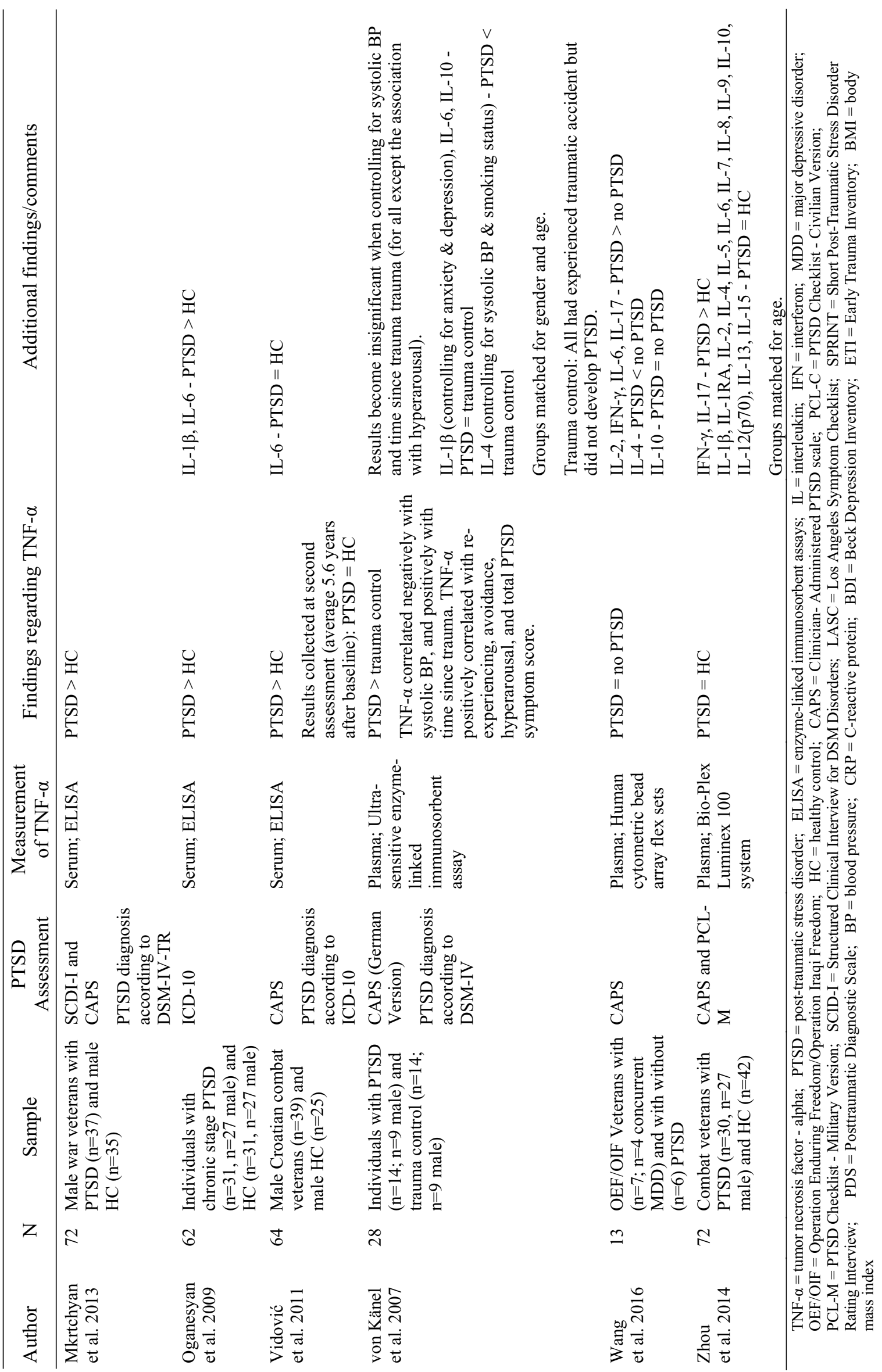




\section{Study findings: Human studies}

\section{Cross-sectional studies assessing TNF- $\alpha$ concentrations in-vivo}

Nineteen cross-sectional studies assessed plasma or serum concentrations of TNF- $\alpha$ in patients with and without PTSD. The findings of these studies are presented in Table 2. All included studies compared concentrations of TNF- $\alpha$ serum or plasma levels between subjects with and without PTSD, with no studies measuring TNF- $\alpha$ in cerebrospinal fluid.

Serum or plasma concentrations of TNF- $\alpha$ were found to be significantly elevated in patients with PTSD compared to individuals without PTSD in 12 of the included studies (von Känel et al. 2007, Hoge et al. 2009, Oganesyan et al. 2009, Vidović et al. 2011, Guo et al. 2012, Hammad et al. 2012, Mkrtchyan et al. 2013, Chen et al. 2014, Lindqvist et al. 2014, Bersani et al. 2016, Devoto et al. 2016, Bruenig et al. 2017). Lindqvist et al. (2017) only identified this pattern at trend level. Furthermore, for one study these results became non-significant when including systolic blood pressure and time since trauma as covariates in their analyses (von Känel et al. 2007). The remaining studies found no difference in concentrations of TNF- $\alpha$ between those with and without PTSD (Gola et al. 2013, Zhou et al. 2014, Himmerich et al. 2015, Jergović et al. 2015, Wang et al. 2016).

Several studies also measured serum or plasma concentrations of other cytokines, including the interleukins (IL) IL-1 $\beta$, IL-2, IL-4, IL-6, IL-8, IL-10, and interferon- $\gamma$ (IFN- $\gamma)$. Overall, results were mixed (see Table 2 for details). A high proportion of studies measuring IL-6 and IL-2 identified elevated concentrations of these cytokines in participants with PTSD, compared to those without. The majority of studies assessing concentrations of IL- $1 \beta$, IFN- $\gamma$, and IL-10 reported no differences between those with and without PTSD. Investigations of IL-4 and IL-8 found contradictory results, observing both elevated and reduced concentrations of these cytokines in those with PTSD, in comparison to a control group. Taken together, these results suggest an elevation of peripherally produced TNF- $\alpha$, as well as other proinflammatory cytokines (IL-6 and IL-2) in patients with PTSD as compared to individuals without PTSD.

\section{Cross-sectional studies investigating stimulated TNF-a production in-vitro}

Five cross-sectional studies measured stimulated TNF- $\alpha$ production in-vitro comparing individuals with and without PTSD (de Kloet et al. 2007, Rohleder et al. 2007, Gill et al. 2008, Gola et al. 2013, Jergović et al. 2014). Details regarding the designs and results of these studies are presented in Table 3. In Jergović et al. (2014), the effects of PTSD on cytokine production of phytohemagglutinin (PHA) stimulated $\mathrm{T}$ cells was investigated. In this study, no difference in spontaneous or stimulated TNF- $\alpha$ production between PTSD patients and healthy controls was detected. Gola et al. (2013) investigated spontaneous and lipopolysaccharide (LPS)-stimulated production of TNF- $\alpha$ in isolated PBMCs. As compared to healthy controls, refugees with PTSD spontaneously produced significantly more TNF- $\alpha$. However, when including smoking as a covariate, this difference reduced to trend level only. Furthermore, no group differences were observed for stimulated TNF- $\alpha$ production. Rohleder et al. (2004) also found no differences between refugees with PTSD and controls in LPSstimulated production of TNF- $\alpha$. In contrast, de Kloet et al. (2007) found that PTSD patients had reduced production of LPS-stimulated TNF- $\alpha$ compared to healthy controls. Gill et al. (2008) measured TNF- $\alpha$ production in PHA and LPS-stimulated whole blood, identifying significantly higher TNF- $\alpha$ production in PTSD patients as compared to healthy controls and trauma controls (experienced a trauma but did not develop PTSD). This was the only study to use exclusively women in their sample. Interestingly, both Gola et al. (2013) and Gill et al. (2008) identified positive correlations between production of TNF- $\alpha$ (unstimulated only in Gola et al.) and PTSD symptom severity/intensity.

\section{Longitudinal studies}

Three longitudinal studies investigating PTSD and TNF- $\alpha$ were identified (see Table 4 for further details). Two studies assessed the impact of specific interventions on TNF- $\alpha$ in people with PTSD (Gocan et al. 2012, Himmerich et al. 2016), with the remaining study measuring TNF- $\alpha$ in combat veterans with chronic PTSD who were receiving treatment-as-usual (Jergović et al. 2015). Himmerich et al. (2016) assessed German soldiers with PTSD, who were randomised to receive either inpatient psychotherapy or outpatient clinical management. It was found that in both treatment groups, serum concentrations of TNF- $\alpha$ increased over the six weeks of treatment. These results remained significant when controlling for medication. In Gocan et al. (2012), soldiers with treatment-resistant PTSD were required to consume a fermented soy formulation (FSWW08) for a 3-month period. In contrast with Himmerich et al. (2016), the intervention resulted in a reduction in TNF- $\alpha$ plasma concentration. In Jergović et al. (2015) serum TNF- $\alpha$ concentration was measured at baseline and after 3 months of treatment-as-usual. No significant differences between these time points were observed. However, TNF- $\alpha$ could not be detected in a high percentage of participant's samples. 
Table 3. Human cross-sectional studies assessing TNF- $\alpha$ production in-vitro in individuals with and without PTSD

\begin{tabular}{|c|c|c|c|c|c|c|}
\hline Author & $\mathrm{N}$ & Sample & $\begin{array}{c}\text { PTSD } \\
\text { Assessment }\end{array}$ & $\begin{array}{l}\text { Measurement of } \\
\text { TNF- } \alpha\end{array}$ & $\begin{array}{c}\text { Findings regarding } \\
\text { TNF- } \alpha\end{array}$ & $\begin{array}{c}\text { Additional } \\
\text { findings/comments }\end{array}$ \\
\hline $\begin{array}{l}\text { de Kloet } \\
\text { et al. } 2007\end{array}$ & 83 & $\begin{array}{l}\text { Male veterans with } \\
\text { PTSD }(n=29 ; n=14 \\
\text { concurrent MDD), } \\
\text { male trauma control } \\
(\mathrm{n}=29 ; \text { veterans } \\
\text { without PTSD) and } \\
\text { male HC }(\mathrm{n}=25)\end{array}$ & CAPS & $\begin{array}{l}\text { Whole blood; NR } \\
\text { Stimuli: LPS }\end{array}$ & $\begin{array}{l}\text { PTSD }<\mathrm{HC} \\
\text { PTSD = trauma } \\
\text { control } \\
\text { Trauma control = } \\
\text { HC } \\
\text { PTSD with MDD = } \\
\text { PTSD without MDD }\end{array}$ & $\begin{array}{l}\text { IL-10 - PTSD }=\mathrm{HC}= \\
\text { trauma control } \\
\text { Groups matched on age, } \\
\text { region and year of } \\
\text { deployment. }\end{array}$ \\
\hline $\begin{array}{l}\text { Gill } \\
\text { et al. } 2008\end{array}$ & 76 & $\begin{array}{l}\text { Females with PTSD } \\
(\mathrm{n}=26 ; \mathrm{n}=13 \\
\text { concurrent MDD), } \\
\text { female trauma } \\
\text { controls }(\mathrm{n}=29 ; \text { past } \\
\text { trauma but no PTSD), } \\
\text { and female HC } \\
\text { ( } \mathrm{n}=21 ; \text { no past trauma } \\
\text { and no PTSD) }\end{array}$ & CAPS & $\begin{array}{l}\text { Whole blood; ELISA } \\
\text { Stimuli: PHA plus } \\
\text { LPS }\end{array}$ & $\begin{array}{l}\text { PTSD > trauma } \\
\text { control } \\
\text { PTSD }>\text { HC } \\
\text { Trauma control = HC } \\
\text { PTSD with MDD > } \\
\text { PTSD without MDD } \\
\text { (trend only) } \\
\text { TNF- } \alpha \text { positively } \\
\text { correlated with PTSD } \\
\text { symptom intensity, } \\
\text { re-experiencing } \\
\text { symptoms, } \\
\text { hyperarousal } \\
\text { symptoms, \& } \\
\text { intensity of } \\
\text { depression. }\end{array}$ & $\begin{array}{l}\text { IL- } 6 \text { - PTSD }>\text { trauma } \\
\text { control; PTSD }>\text { HC } \\
\text { IL- } 1 \beta \text { - PTSD }=\mathrm{HC}= \\
\text { trauma control } \\
\text { Controlled for age, BMI } \\
\text { and smoking. }\end{array}$ \\
\hline $\begin{array}{l}\text { Gola } \\
\text { et al. } 2013\end{array}$ & 34 & 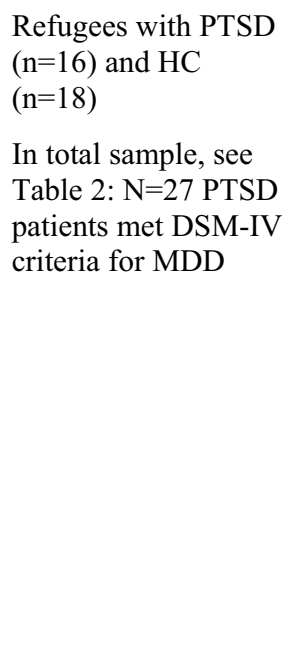 & $\begin{array}{l}\text { CAPS } \\
\text { PTSD } \\
\text { diagnosis } \\
\text { according to } \\
\text { DSM-IV }\end{array}$ & $\begin{array}{l}\text { PBMCs; Multiplex } \\
\text { bead-based assays } \\
\text { Stimuli: LPS or } \\
\text { unstimulated }\end{array}$ & $\begin{array}{l}\text { Unstimulated: PTSD } \\
\text { > HC } \\
\text { LPS-stimulated: } \\
\text { PTSD = HC } \\
\text { Unstimulated TNF- } \alpha \\
\text { production positively } \\
\text { correlated with PTSD } \\
\text { symptom severity. }\end{array}$ & $\begin{array}{l}\text { Unstimulated TNF- } \alpha \\
\text { results reduced to trend } \\
\text { level when smoking } \\
\text { included as a covariate. } \\
\text { LPS-stimulated results } \\
\text { remained true when } \\
\text { including sex or smoking } \\
\text { as a covariate. } \\
\text { Unstimulated: IL-1 } \beta \text {, IL-6 } \\
\text { - PTSD > HC } \\
\text { LPS-stimulated: IL-1 } \beta \text { - } \\
\text { PTSD = HC; IL-6 - PTSD } \\
>\text { HC } \\
\text { Groups matched on } \\
\text { ethnicity. } \\
\text { See also Table } 2 \text { for in- } \\
\text { vivo cross-sectional data }\end{array}$ \\
\hline $\begin{array}{l}\text { Jergović } \\
\text { et al. } 2014\end{array}$ & 101 & $\begin{array}{l}\text { Male combat veterans } \\
\text { with PTSD }(n=30 ; \\
n=24 \text { concurrent } \\
\text { MDD) and male HC } \\
(n=17)\end{array}$ & $\begin{array}{l}\text { CAPS } \\
\text { PTSD } \\
\text { diagnosis } \\
\text { according to } \\
\text { ICD-10 }\end{array}$ & $\begin{array}{l}\text { PBMCs; NR } \\
\text { Stimuli: LPS or } \\
\text { unstimulated }\end{array}$ & $\mathrm{PTSD}=\mathrm{HC}$ & $\begin{array}{l}\text { Stimulated: IFN- } \gamma \text {, IL-2, } \\
\text { IL-4 - PTSD=HC } \\
\text { Unstimulated: IL-4 - } \\
\text { PTSD = HC; IFN- } \gamma \text {, IL-2 } \\
\text { - PTSD < HC } \\
\text { Telomere length - PTSD } \\
<\text { HC } \\
\text { Groups matched on age. }\end{array}$ \\
\hline $\begin{array}{l}\text { Rohleder } \\
\text { et al. } 2004\end{array}$ & 25 & $\begin{array}{l}\text { Bosnian refugees with } \\
\text { PTSD }(n=12, n=7 \\
\text { males; } n=2 \text { concurrent } \\
\text { MDD) and HC ( } n=13, \\
n=5 \text { males })\end{array}$ & $\begin{array}{l}\text { SCL-90R and } \\
\text { HTQ } \\
\text { PTSD } \\
\text { diagnosis } \\
\text { according to } \\
\text { DSM-IV }\end{array}$ & $\begin{array}{l}\text { Whole blood; ELISA } \\
\text { Stimuli: LPS }\end{array}$ & $\mathrm{PTSD}=\mathrm{HC}$ & $\begin{array}{l}\text { IL- } 6 \text { - PTSD }>\text { HC } \\
\text { Groups matched for age } \\
\text { and gender. }\end{array}$ \\
\hline
\end{tabular}

TNF- $\alpha=$ tumor necrosis factor - alpha; PTSD = post-traumatic stress disorder; ELISA = enzyme-linked immunosorbent assays; IL = interleukin; $\mathrm{IFN}=$ interferon; MDD = major depressive disorder; $\mathrm{HC}=$ healthy control; $\mathrm{NR}=$ not reported; CAPS = Clinician- Administered PTSD scale; $\mathrm{BMI}=$ body mass index; HTQ = Harvard Trauma Questionnaire; SCL-90R = Symptom Checkist-90-Revised;

$\mathrm{PBMC}=$ peripheral blood mononuclear cell; LPS = lipopolysaccharide; PHA = phytohaemagglutinin 
Table 4. Human longitudinal studies assessing TNF- $\alpha$ concentration in individuals with PTSD

\begin{tabular}{|c|c|c|c|c|c|c|c|}
\hline Author & $\mathrm{N}$ & Sample & Intervention & $\begin{array}{c}\text { PTSD } \\
\text { Assessment }\end{array}$ & $\begin{array}{c}\text { Measurement } \\
\text { of TNF- } \alpha\end{array}$ & $\begin{array}{c}\text { Findings } \\
\text { regarding TNF- } \alpha\end{array}$ & $\begin{array}{c}\text { Additional } \\
\text { findings/comments }\end{array}$ \\
\hline $\begin{array}{l}\text { Gocan } \\
\text { et al. } 2012\end{array}$ & 10 & $\begin{array}{l}\text { Male treatment- } \\
\text { resistant soldiers } \\
\text { with combat- } \\
\text { related PTSD }\end{array}$ & $\begin{array}{l}\text { Consumption } \\
\text { of a fermented } \\
\text { soy } \\
\text { formulation: } \\
\text { FSWW08 } \\
\text { (120ml daily) }\end{array}$ & $\begin{array}{l}\text { CAPS } \\
\text { PTSD } \\
\text { diagnosis } \\
\text { according to } \\
\text { ICD-10 }\end{array}$ & $\begin{array}{l}\text { Plasma; ELISA } \\
\text { At baseline (T0) } \\
\text { and after } \\
\text { intervention ( } 3 \\
\text { months; T1) }\end{array}$ & $\mathrm{T} 0>\mathrm{T} 1$ & $\begin{array}{l}\text { IL- } 1 \beta, \text { IFN- } \gamma-\text { T0 }> \\
\text { T1 } \\
\text { IL-6 - T0 = T1 } \\
\text { CAPS score - T0 > } \\
\text { T1 }\end{array}$ \\
\hline $\begin{array}{l}\text { Himmerich } \\
\text { et al. } 2016\end{array}$ & 38 & $\begin{array}{l}\text { Male German } \\
\text { soldiers with } \\
\text { PTSD } \\
\text { NB recruited from } \\
\text { Himmerich et al. } \\
(2015,2016) \text { - See } \\
\text { Table } 1\end{array}$ & $\begin{array}{l}\text { Randomised to } \\
\text { receive imme- } \\
\text { diate inpatient } \\
\text { psychotherapy } \\
(\mathrm{n}=21) \text { or } \\
\text { outpatient } \\
\text { clinical } \\
\text { management } \\
\text { control group } \\
(\mathrm{n}=17)\end{array}$ & PDS & $\begin{array}{l}\text { Serum; Bio-Plex } \\
\text { Pro }{ }^{\mathrm{TM}} \text { human } \\
\text { cytokine } \\
\text { immunoassay } \\
\text { At baseline (T0) } \\
\text { and after treat- } \\
\text { ment (six weeks; } \\
\text { T1) }\end{array}$ & $\begin{array}{l}\text { T0 }<\mathrm{T} 1 \\
\text { No correlations } \\
\text { between change } \\
\text { in PDS score and } \\
\text { change in TNF- } \alpha\end{array}$ & $\begin{array}{l}\text { sTNF-R p55, sTNF-R } \\
\text { p75 - T0 }>\text { T1 } \\
\text { PDS score - T0 > T1 } \\
\text { Results remained } \\
\text { significant when } \\
\text { controlling for } \\
\text { medication. }\end{array}$ \\
\hline $\begin{array}{l}\text { Jergović } \\
\text { et al. } 2015\end{array}$ & 69 & $\begin{array}{l}\text { Male Croatian } \\
\text { combat veterans } \\
\text { with PTSD }\end{array}$ & N/A TAU & $\begin{array}{l}\text { LASC } \\
\text { PTSD diagnosis } \\
\text { according to } \\
\text { ICD-10 }\end{array}$ & $\begin{array}{l}\text { Serum; Bead- } \\
\text { based multiplex } \\
\text { immunoassay } \\
\text { At baseline (T0) } \\
\text { and after } 3 \\
\text { months (T1) }\end{array}$ & $\begin{array}{l}\mathrm{T} 0=\mathrm{T} 1 \\
\mathrm{TNF}-\alpha \text { not } \\
\text { detected in high } \\
\text { percentage of } \\
\text { participants }\end{array}$ & $\begin{array}{l}\text { See Table } 2 \text { for in- } \\
\text { vivo cross-sectional } \\
\text { data. }\end{array}$ \\
\hline
\end{tabular}

TNF- $\alpha=$ tumor necrosis factor - alpha; PTSD = post-traumatic stress disorder; ELISA = enzyme-linked immunosorbent assays; $\mathrm{IL}=$ interleukin; IFN = interferon; CAPS = Clinician- Administered PTSD scale; LASC = Los Angeles Symptom Checklist; PDS = Posttraumatic Diagnostic Scale; sTNF-R = soluble tumor necrosis receptor; $\mathrm{T} 0$ = baseline time point; T1 = first time point; $\mathrm{N} / \mathrm{A}=$ not applicable; TAU $=$ treatment-as-usual

\section{DISCUSSION}

\section{Summary of findings}

\section{TNF- $\alpha$ in animal models of PTSD}

Elevated levels of TNF- $\alpha$ (mRNA and protein levels) in the hippocampus of stressed rats, as compared to non-stressed rats were identified in two of the three included animal studies (Levkowitz et al. 2015, Lee et al. 2016). Furthermore, the increased levels of TNF- $\alpha$ were not observed in the frontal cortex or hypothalamus (Levkowitz et al. 2015). The finding of elevated levels of TNF- $\alpha$ production in the hippocampus of stressed rats is very interesting in light of the literature derived from human studies that reports the hippocampus to be implicated in PTSD, in terms of both volume and function (e.g. Kitayama et al. 2005, Woon et al. 2010, O'Doherty et al. 2015, van Rooij et al. 2015). Taken together, these findings suggest a potential pathophysiological role of hippocampal TNF- $\alpha$ production in the development of PTSD. Interestingly, when the stressed rats were administered medication with antiinflammatory properties, the elevated TNF- $\alpha$ concentration reduced to the level of non-stressed rats (Levkowitz et al. 2015, Lee et al. 2016). Furthermore, this coincided with a reduction of anxiety-like behaviours in the treated rats (but not in the stressed non-treated rats) which returned to a similar level to that seen in the non-stressed rats. This highlights the therapeutic potential that immunomodulatory drugs could have for the treatment of PTSD.

\section{TNF- $\alpha$ in human studies of PTSD}

In accord with previous reviews and meta-analyses (Passos et al. 2015, Wang \& Young 2016), concentrations of TNF- $\alpha$ in the plasma and serum of patients with PTSD were found to be elevated, as compared to healthy controls. Only one study demonstrated a loss of their initial statistical significance when including covariates in the analyses (von Känel et al. 2007). It is of note that in two of the remaining studies that found no difference in TNF- $\alpha$ concentrations between groups, TNF- $\alpha$ was not detectable in a high percentage of participants (Gola et al. 2013, Jergović et al. 2015), which may account for their findings. The results of invitro investigations of TNF- $\alpha$ in PTSD were generally inconsistent. This is likely due to the heterogeneous methodologies used in these studies, specifically in relation to the measurement of TNF- $\alpha$ and the heterogeneity of the sample.

It is of interest to note that concentrations and/or production of TNF- $\alpha$ and other cytokines have been shown to be correlated with PTSD symptom severity (von Känel et al. 2007, Gill et al. 2008, Gola et al. 2013, Dennis et al. 2016). Specifically, concentrations of TNF- $\alpha$ (measured using both in-vivo and in-vitro methods) positively correlated with severity/intensity of PTSD symptoms (Gill et al. 2008, Gola et al. 2013, Bruenig et al. 2017) and severity and/or frequency of specific symptoms, including re-experiencing (Gill et al. 2008) and hyperarousal (von Känel et al. 2007, Gill et al. 2008). In von Känel et al. (2007), after including 
covariates in the analyses, the association only remained with hyperarousal symptoms. Given the many possible symptom combinations that are presented by individuals with PTSD (Galatzer-Levy \& Bryant 2013), future research needs to consider whether inflammation is only associated with certain symptoms (O’Donovan 2016).

An increase of the production of pro-inflammatory cytokines, like TNF- $\alpha$, has been found in a number of studies in which hyperproduction of TNF- $\alpha$ was induced by acute and chronic stress paradigms (Cosen-Binker et al. 2004, Binker et al. 2010, Liu et al. 2012, Vorhees et al. 2013). More specifically, animal studies with rats have shown that TNF- $\alpha$ plasma concentration increased during acute and chronic (Himmerich et al. 2013), as well as social stress (Krügel et al. 2014). However, the mechanism as to how stress leads to an increase of proinflammatory cytokine production is still unclear. There is evidence from the literature for several pathways by which TNF- $\alpha$ and other cytokines might have an effect on the brain (Quan 2008). They have been shown to be able to activate the HPA axis, to activate neuronal serotonin transporters, to stimulate the indoleamine 2,3dioxygenase, to contribute to the destruction of neurons, and/or to release glutamate (Zhu et al. 2006, Wichers \& Maes 2002, Himmerich et al. 2009, Curran \& O’Connor 2001). Therefore, stress, by inducing an increased production of pro-inflammatory cytokines, might trigger neurobiological changes, which could, as a consequence, induce psychiatric disorders such as PTSD and depression.

Taken together, it could be suggested that elevated concentrations of TNF- $\alpha$ could be a biomarker of PTSD. It is important to consider that TNF- $\alpha$ may not a specific biomarker for PTSD, but rather a general marker of psychopathology. Elevated levels of TNF- $\alpha$ have also been observed in other psychiatric disorders, including depression (Himmerich et al. 2008, Schmidt et al. 2014). Furthermore, given that TNF- $\alpha$ is part of a complex network of cytokines, which have also been shown to be elevated in PTSD and other disorders (e.g. Guo et al. 2012, Hammad et al. 2012, Schmidt et al. 2014, Bersani et al 2016), a combination of several cytokines may be the best indicator.

The data derived from longitudinal studies is difficult to interpret given the mixed findings. One study that assessed the effect of inpatient psychotherapy and clinical management found an increase in TNF- $\alpha$ concentration over 6 weeks of treatment (Himmerich et al. 2016). In contrast, daily consumption of a fermented soy formulation resulted in a decrease in TNF- $\alpha$ concentrations over the 3-month intervention (Gocan et al. 2012). However, these studies had small samples and did not include a control group. Therefore, it is unclear whether the participants with PTSD had elevated concentrations of TNF- $\alpha$ in comparison to healthy controls, prior to starting the intervention. Furthermore, the heterogeneity in treatment interventions means that they are not directly comparable. Interestingly, both interventions were shown to reduce participant's scores on PTSD symptom measures. This suggests that TNF- $\alpha$ could potentially serve as a state marker of PTSD, given the changes in concentrations observed in response to different interventions. An additional longitudinal study found no difference in TNF- $\alpha$ concentrations between baseline assessment and after 3 months of treatment-asusual (Jergović et al. 2015). However, in this study TNF- $\alpha$ were not detected in a high percentage of participants, so conclusions cannot be drawn. As can be seen, there is limited data on longitudinal TNF- $\alpha$ concentrations in treatment studies of PTSD. Therefore, future research would benefit from measuring TNF- $\alpha$ over the treatment course to gain a clearer understanding of how TNF- $\alpha$ is related to treatment response. Prospective studies would also be of benefit, given not everyone who is exposed to a traumatic event will go on to develop PTSD (Keane et al. 2009). This may be best suited to a military setting in which cytokines could be measured prior to and after deployment with additional follow-up assessments. This will help to elucidate the role of cytokines in PTSD and to determine whether elevated TNF- $\alpha$ is a state or trait marker of PTSD.

\section{Methodological considerations}

The findings emerging from this review must be interpreted with caution and in light of several methodological considerations. Firstly, the human studies presented here used a range of assessments to diagnose and/or measure PTSD symptomology. Assessment measures vary considerably on factors such as number of items, response format (i.e. self-report vs. interview), and the anchoring of the measure (i.e. is it anchored to a specific traumatic event, broader stressful experiences, or stressful military experience). With regards to PTSD symptom severity, this may make comparing the findings of studies difficult.

Secondly, while some studies age-matched participants and controlled for certain covariates in their analyses, the majority of the included studies did not account for pre-analytical factors that may affect the concentration of certain cytokines. These include factors such as age, BMI, smoking, medication, and concurrent diagnoses relating to physical and mental health (Dugué et al. 1994). Several studies within this review highlight the importance of this practice, finding that previously significant results became non-significant when covarying for certain factors in their analyses (e.g. systolic blood pressure: von Känel et al. 2007; smoking: Gola et al. 2013). Furthermore, recent meta-analyses have shown that TNF- $\alpha$ was found to be elevated in those with PTSD as compared to controls, but only when participants with comorbid depression or participants who were on medication were excluded from analyses (Passos et al. 2015, O'Donavon 2016). Thus, future studies need to carefully consider factors that may influence the measurement of cytokine concentrations and account for them within their study design and analyses. 
Thirdly, the specific methodologies used to measure cytokine concentrations and production varies considerably between studies. These include using different sample types (e.g. for in-vivo: plasma, serum; for invitro: PBMCs, whole blood) and different equipment for measuring cytokine concentrations (e.g. ELISA, multiplex arrays). This is problematic as different methodologies may yield different results (see Zhou et al. 2015 for a review on methodological issues affecting cytokine measurement). For example, research has shown that concentrations of cytokines significantly differ between plasma and serum samples (Guo et al. 2013). As a result, the findings from these studies may not be directly comparable.

Finally, the majority of the samples in the included studies have small samples and participants are limited to males and to those suffering from PTSD due to war i.e. veterans and refugees. Therefore, we cannot be sure that the presented findings will apply to those experiencing PTSD due to being exposed to a different trauma e.g. accident, natural disasters, terrorist attacks (Wang \& Young 2016). Also, some studies used a trauma control group (i.e. they were exposed to trauma but did not go on to develop PTSD; e.g. von Känel et al. 2007, Bruenig et al. 2017) as opposed to healthy control group (i.e. no experience of trauma). At this point, it is unclear as to what extent trauma exposure can influence inflammatory markers in the long-term, even without the development of PTSD (Passos et al. 2015).

\section{CONCLUSIONS}

To our knowledge, this is the first systematic review considering the specific role of TNF- $\alpha$ in PTSD. The current review indicates that (i) generally serum and plasma concentrations of TNF- $\alpha$ are elevated in those with PTSD in comparison to those without; thus suggesting that TNF- $\alpha$ may be a potential biomarker of PTSD and serve as a potential therapeutic target for PTSD (Neigh \& Ali 2016); (ii) TNF- $\alpha$ production in the hippocampus may be involved in the underlying pathophysiology of PTSD; and (iii) in animal models of PTSD, anxiety-like behaviour can be altered by immunomodulatory drugs, which highlights the future potential of this medication for the treatment of PTSD. However, these findings do need to be interpreted in view of methodological issues and the potential for publication bias (Thornton \& Lee 2000). Longitudinal research is needed to understand the state/trait related nature of TNF- $\alpha$ concentrations in PTSD. This will enlighten us to the potential biological mechanisms underlying PTSD, which may be responsible for the development and/or maintenance of the disorder, elucidate if cytokine concentrations could be a potential marker of treatment response, and may provide the basis for further investigations into immunomodulatory medication as a treatment for PTSD.

\section{Acknowledgements: None.}

\section{Conflict of interest: None to declare.}

\section{Contribution of individual authors:}

Serkan Hussein, Gerd D. Willmund, Mohammad A. A. Ibrahim \& Hubertus Himmerich designed the study;

Serkan Hussein, Bethan Dalton \& Hubertus Himmerich performed the literature search, the content-related analysis of the obtained relevant publications and drafted the manuscript;

All authors contributed to the interpretation of the results, revised the first draft of the manuscript and approved its final version.

\section{References}

1. American Psychiatric Association (APA): Diagnostic and statistical manual of mental disorders $\left(5^{\text {th }}\right.$ ed.). American Psychiatric Publishing, Arlington, VA, 2013.

2. Andrews JA \& Neises KD: Cells, biomarkers, and posttraumatic stress disorder: evidence for peripheral involvement in a central disease. J Neurochem 2012; 120:26-36.

3. Bailey CR, Cordell E, Sobin SM \& Neumeister A: Recent progress in understanding pathophysiology of posttraumatic stress disorder. CNS Drugs 2013, 27:221-232.

4. Balõtšev $R$, Koido K, Vasar V, Janno S, Kriisa K, Mahlapuu $R$ et al.: Inflammatory, cardio-metabolic and diabetic profiling of chronic schizophrenia. Eur Psychiatry 2016; 39:1-10.

5. Bersani FS, Wolkowitz OM, Lindqvist D, Yehuda R, Flory $J$, Bierer LM et al.: Global arginine bioavailability, a marker of nitric oxide synthetic capacity, is decreased in PTSD and correlated with symptom severity and markers of inflammation. Brain Behav Immun 2016; 52:153-160.

6. Binker MG, Binker-Cosen AA, Richards D, Gaisano HY, de Cosen RH \& Cosen-Binker LI. Chronic stress sensitizes rats to pancreatitis induced by cerulein: role of TNFalpha. World J Gastroenterol 2010; 16:5565-5581.

7. Blake DD, Weathers FW, Nagy LM, Kaloupek DG, Gusman FD, Charney DS et al.: The development of a clinician-administered PTSD scale. J Trauma Stress 1995; 8:75-90.

8. Blanchard EB, Jones-Alexander J, Buckley TC \& Forneris CA: Psychometric properties of the PTSD checklist (PCL). Behav Res Ther 1996; 34:669-673.

9. Breslau N, Davis GC, Peterson EL \& Schultz L: Psychiatric sequelae of posttraumatic stress disorder in women. Arch Gen Psychiatry 1997; 54:81-87.

10. Bruenig D, Mehta D, Morris CP, Harvey W, Lawford B, Young RM et al.: Genetic and serum biomarker evidence for a relationship between TNF $\alpha$ and PTSD in Vietnam war combat veterans. Compr Psychiatry 2017; 74:125-133.

11. Chen T, Guo M, Gao Y, Chen F, Guo J, Liu T et al.: A comparative study on the levels of serum cytokines and cortisol among post-traumatic stress disorder patients of Li and Han ethnicities in Hainan. Chin Med J (Engl) 2014; 127:2771-2774. 
12. Connor KM \& Davidson JR: SPRINT: a brief global assessment of post-traumatic stress disorder. Int Clin Psychopharmacol. 2001; 16:279-284.

13. Cosen-Binker LI, Binker MG, Negri G \& Tiscornia O: Influence of stress in acute pancreatitis and correlation with stress-induced gastric ulcer. Pancreatology 2004; 4:470-484.

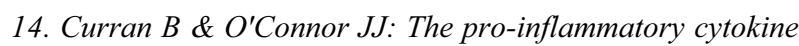
interleukin-18 impairs long-term potentiation and NMDA receptor-mediated transmission in the rat hippocampus in vitro. Neuroscience 2001; 108:83-90.

15. Decourt B, Lahiri DK \& Sabbagh MN: Targeting Tumor Necrosis Factor Alpha for Alzheimer's Disease. Curr Alzheimer Res 2017; 14:412-425.

16. de Kloet CS, Vermetten E, Bikker A, Meulman E, Gueze E, Havelaars et al.: Leukocyte glucocorticoid receptor expression and immunoregulation in veterans with and without post-traumatic stress disorder. Mol Psychiatry 2007; 12: 443-453.

17. Dennis PA, Weinberg JB, Calhoun PS, Watkins LL, Sherwood A, Dennis MF et al.: An investigation of vagoregulatory and health-behavior accounts for increased inflammation in posttraumatic stress disorder. J Psychosom Res 2016; 83:33-39.

18. Devoto C, Arcurio L, Fetta J, Ley M, Rodney T, Kanefsky $R Z$ et al.: Inflammation Relates to Chronic Behavioral and Neurological Symptoms in Military with Traumatic Brain Injuries. Cell Transplant 2016.

19. Dugué B, Leppänen E \& Gräsbeck R: Preanalytical factors and the measurement of cytokines in human subjects. Int J Clin Lab Res 1996; 26: 99.

20. Foa EB, Cashman L, Jaycox L \& Perry K: The validation of a self-report measure of PTSD: The Posttraumatic Diagnostic Scale. Psychol Assess 1997; 9: 445-451.

21. Frans $O$, Rimmö PA, Aberg L \& Fredrikson M: Trauma exposure and post traumatic stress disorder in the general population. Acta Psychiatr Scand 2005; 111:291-299.

22. Galatzer-Levy IR \& Bryant RA: 636,120 ways to have posttraumatic stress disorder. Perspect Psychol Sci 2013; 8:651-662.

23. Gill J, Vythilingam $M \&$ Page GG: Low cortisol, high DHEA, and high levels of stimulated TNF-alpha, and IL-6 in women with PTSD. J Trauma Stress 2008; 21:530-539.

24. Gocan AG, Bachg D, Schindler AE \& Rohr UD: Balancing steroidal hormone cascade in treatmentresistant veteran soldiers with PTSD using a fermented soy product (FSWW08): a pilot study. Horm Mol Biol Clin Investig 2012; 10:301-314.

25. Gola H, Engler H, Sommershof A, Adenauer H, Kolassa S, Schedlowski $M$ et al.: Posttraumatic stress disorder is associated with an enhanced spontaneous production of pro-inflammatory cytokines by peripheral blood mononuclear cells. BMC Psychiatry 2013; 13:40.

26. Guo G-H, Dong J, Yuan X-H, Dong Z-N \& Tian Y-P: Clinical evaluation of the levels of 12 cytokines in serum/plasma under various storage conditions using evidence biochip arrays. Mol Med Reports 2013; 7:775780.

27. Guo M, Liu T, Guo JC, Jiang XL, Chen F \& Gao YS: Study on serum cytokine levels in posttraumatic stress disorder patients. Asian Pac J Trop Med 2012; 5:323-325.

28. Hammad SM, Truman JP, Al Gadban MM, Smith KJ, Twal WO \& Hamner MB: Altered blood sphingolipi- domics and elevated plasma inflammatory cytokines in combat veterans with post-traumatic stress disorder. Neurobiol Lipids 2012; 10: 2.

29. Himmerich H, Berthold-Losleben $M \&$ Pollmächer T. The relevance of the TNF-alpha system in psychiatric disorders. Fortschr Neurol Psychiatr 2009; 77: 334-345.

30. Himmerich H, Fischer J, Bauer K, Kirkby KC, Sack U \& Krügel U: Stress-induced cytokine changes in rats. Eur Cytokine Netw. 2013 ; 24: 97-103

31. Himmerich H, Fulda S, Linseisen J, Seiler H, Wolfram $G$, Himmerich $S$ et al.: Depression, comorbidities and the TNF-alpha system. Eur Psychiatry 2008; 23: 421-429.

32. Himmerich H, Willmund GD, Zimmermann P, Wolf JE, Bühler AH, Holdt LM et al.: Serum concentrations of TNF-a, sTNF-R p55 and $p 75$ and post-trauamtic stress in German soldiers. Eur Cytokine Netw 2015; 26: 57-60.

33. Himmerich H, Willmund GD, Zimmermann P, Wolf JE, Bühler AH, Kirkby KC et al.: Serum concentrations of $T N F-\alpha$ and its soluble receptors during psychotherapy in German soldiers suffering from combat-related PTSD. Psychiatr Danub 2016; 28: 293-298.

34. Hoge EA, Brandstetter K, Moshier S, Pollach MH, Wong, KK \& Simon NM. Broad spectrum of cytokine abnormalities in panic disorders and posttraumatic stress disorder. Depress Anxiety 2009; 26: 447-455.

35. Idriss HT \& Naismith JH: TNF alpha and the TNF receptor superfamily: structure-function relationship(s). Microsc Res Tech 2000; 50: 184-195.

36. Jergović $M$, Bendelja $K$, Savić Mlakar A, Vojvoda $V$, Aberle $N$, Jovanovic $T$ et al.: Circulating levels of hormones, lipids, and immune mediators in post-traumatic stress disorder - a 3-month follow-up study. Front Psychiatry 2015; 6:4.

37. Jergović M, Tomičević M, Vidović A, Bendelja K, Savić A, Vojvoda $V$ et al.: Telomere shortening and immune activity in war veterans with posttraumatic stress disorder. Prog Neuropsychopharmacol Biol Psychiatry 2014; 54: 275-283.

38. Keane TM, Marx BP \& Sloan DM. Post-traumatic stress disorder: definition, prevalence, and risk factors. In Shiromani PJ, Keane TM, LeDoux JE (eds): PostTraumatic Stress Disorder: Basic Science and Clinical Practice, 1-19. Humana Press, 2009.

39. King LA, King DW, Leskin GA \& Foy DW: The Los Angeles Symptom checklist: a self-report measure of posttraumatic stress disorder. Assessment 1995; 2:1-17.

40. Kitayama N, Vaccarino V, Kutner M, Weiss $P$ \& Bremner JD: Magnetic resonance imaging (MRI) measurement of hippocampal volume in posttraumatic stress disorder: a meta-analysis. J Affect Disord 2005; 88:79-86.

41. Krügel U, Fischer J, Bauer K, Sack U \& Himmerich H: The impact of social isolation on immunological parameters in rats. Arch Toxicol. 2014; 88: 853-855.

42. Lebrec H, Ponce R, Preston BD, Iles J, Born TL \& Hooper M: Tumor necrosis factor, tumor necrosis factor inhibition, and cancer risk. Curr Med Res Opin 2015; 31 : 557-574.

43. Lee B, Sur B, Yeom M, Shim I, Lee H \& Hahm DH: Effects of systemic administration of ibuprofen on stress response in a rat model of post-traumatic stress disorder. Korean $J$ Physiol Pharmacol 2016; 20: 357-366.

44. Levkovitz Y, Fenchel D, Kaplan Z, Zohar J \& Cohen H: Early post-stressor intervention with minocycline, a se- 
cond-generation tetracycline, attenuates post-traumatic stress response in an animal model of PTSD. Eur Neuropsychopharmacol 2015; 25:124-132.

45. Lichtblau N, Schmidt FM, Schumann R, Kirkby KC \& Himmerich H: Cytokines as biomarkers in depressive disorder: current standing and prospects. Int Rev Psychiatry 2013; 25:592-603.

46. Lindqvist D, Dhabhar FS, Mellon SH, Yehuda R, Grenon $S M$, Flory JD et al.: Increased pro-inflammatory milieu in combat related PTSD - A new cohort replication study. Brain Behav Immun 2017; 59:260-264.

47. Lindqvist D, Wolkowitz OM, Mellon S, Yehuda R, Flory JD, Henn-Haase $C$ et al.: Proinflammatory milieu in combat-related PTSD is independent of depression and early life stress. Brain Behav Immun 2014; 42:81-88.

48. Liu FF, Yang LD, Sun XR, Zhang H, Pan W, Wang XM et al.: NOX2 Mediated-Parvalbumin Interneuron Loss Might Contribute to Anxiety-Like and Enhanced Fear Learning Behavior in a Rat Model of Post-Traumatic Stress Disorder. Mol Neurobiol 2016; 53:6680-6689.

49. Liu YL, Bi H, Fan R, Li YH, Wang YM, Chen YM et al.: Effect of compound nutrients on acute immobilization and cold water-immersion stress-induced changes of Th1/Th2 cytokines. Xi Bao Yu Fen Zi Mian Yi Xue Za Zhi 2012; 28. 601-603.

50. Lorz C \& Mehmet H: The role of death receptors in neural injury. Front Biosci 2009; 14: 583-595.

51. Mkrtchyan GM, Boiadzhian AS, Avetian DG \& Sukiasian $S G$ : The involvement of abnormal apoptosis in the disturbance of synaptic plasticity in posttraumatic stress disorder. Zh Nevrol Psikhiatr Im S S Korsakova 2013; 113: 26-29.

52. Moher D, Liberati A, Tetzlaff J, Altman DG \& The PRISMA Group: Preferred reporting items for systematic reviews and meta-analyses: The PRISMA statement. PLoS Med 2009; 6; e1000097.

53. Neigh GN \& Ali FF: Co-morbidity of PTSD and immune system dysfunction: opportunities for treatment. Current Opinion in Pharmacology 2016; 29: 104-110.

54. O'Doherty DC, Chitty KM, Saddiqui S, Bennett MR \& Lagopoulos J: A systematic review and meta-analysis of magnetic resonance imaging measurement of structural volumes in posttraumatic stress disorder. Psychiatry Res 2015;232:1-33.

55. O'Donovan A: PTSD is associated with elevated inflammation. Any impact on clinical practice? Evid Based Ment Health 2016; 19:120-122.

56. Oganesyan LP, Mkrtchyan GM, Sukiasyan SH \& Boyajyan AS: Classic and alternative complement cascades in post-traumatic stress disorder. Bull Exp Biol Med 2009; 148:859-861.

57. Passos IC, Vasconcelos-Moreno MP, Costa LG, Kunz M, Brietzke E, Quevedo J et al.: Inflammatory markers in post-traumatic stress disorder: a systematic review, metaanalysis, and meta-regression. Lancet Psychiaty 2015; 2: 1002-1012.

58. Pitman RK, Rasmusson AM, Koenen KC, Shin LM, Orr SP, Gilbertson $M W$ et al.: Biological studies of posttraumatic stress disorder. Nat Rev Neurosci 2012; 13. 769-787.

59. Quan N: Immune-to-brain signaling: how important are the blood-brain barrier-independent pathways? Mol Neurobiol 2008; 37: 142-152.
60. Rohleder N, Joksimovic L, Wolf JM \& Kirschbaum C: Hypocortisolism and increased glucocorticoid sensitivity of pro-inflammatory cytokine production in Bosnian war refugees with posttraumatic stress disorder. Biol Psychiatry 2004; 55: 745-751.

61. Ryan J, Chaudieu I, Ancelin ML \& Saffery R: Biological underpinnings of trauma and post-traumatic stress disorder: focusing on genetics and epigenetics. Epigenomics 2016; 8:1553-1569.

62. Sheeran $T \&$ Zimmerman M: Screening for posttraumatic stress disorder in a general psychiatric outpatient setting. J Consult Clin Psychol. 2002; 70: 961-966.

63. Schmidt FM, Lichtblau N, Minkwitz J, Chittka T, Thormann J, Kirkby KC et al.: Cytokine levels in depressed and non-depressed subjects, and masking effects of obesity. J Psychiatr Res 2014; 55: 29-34.

64. Spitzer RL, Williams JB, Gibbon M, First MB: The Structured Clinical Interview for DSM-III-R (SCID). I: History, rationale, and description. Arch Gen Psychiatry. 1992; 49: 624-629.

65. Thornton A \& Lee P: Publication bias in meta-analysis: its causes and consequences. J Clin Epidemiol 2000; 53: 207-216.

66. Ventura J, Liberman RP, Green MF, Shaner A \& Mintz J: Training and quality assurance with the Structured Clinical Interview for DSM-IV (SCID-I/P). Psychiatry Res 1998; 79: 163-173.

67. Vidović A, Gotovac K, Vilibić M, Sabioncello A, Jovanović $T$, Rabatić $S$ et al.: Repeated assessments of endocrine \& immune-related changes in posttraumatic stress disorder. Neuroimmunomodulation 2011; 18: 199-211.

68. von Känel R, Hepp U, Kraemer B, Traber R, Keel M, Mica $L$ et al.: Evidence for low-grade systemic proinflammatory activity in patients with posttraumatic stress disorder. $J$ Psychiatr Res 2007; 41: 744-752.

69. Voorhees JL, Tarr AJ, Wohleb ES, Godbout JP, Mo X, Sheridan JF et al.: Prolonged restraint stress increases $I L-6$, reduces $I L-10$, and causes persistent depressive-like behavior that is reversed by recombinant IL-10. PLoS One 2013; 8: e58488.

70. Wang Z, Mandel H, Levingston CA \& Young MRI: An exploratory approach demonstrating immune skewing and a loss of coordination among cytokines in plasma and saliva of Veterans with combat-related PTSD. Human Immunology 2016; 77: 652-657.

71. Wang $Z$ \& Young MRI: PTSD, a disorder with an immunological component. Front Immunol 2016; 7: 219-224.

72. Weathers FW, Litz BT, Keane TM, Palmieri PA, Marx BP \& Schnurr PP: The PTSD Checklist for DSM-5 (PCL-5). 2013. Scale available from the National Center for PTSD at www.ptsd.va.gov.

73. Wichers $M \&$ Maes $M$ : The psychoneuroimmuno-pathophysiology of cytokine-induced depression in humans. Int J Neuropsychopharmacol 2002; 5: 375-388.

74. Woon FL, Sood $S \&$ Hedges DW: Hippocampal volume deficits associated with exposure to psychological trauma and posttraumatic stress disorder in adults: a metaanalysis. Prog Neuropsychopharmacol Biol Psychiatry 2010; 34:1181-1188.

75. World Health Organization (WHO). International Statistical Classification of Diseases and Related Health Problems; Tenth Revision. Geneva: World Health Organization, 1992. 
76. Yehuda $R \&$ McFarlane AC: Conflict between current knowledge about posttraumatic stress disorder and its original conceptual basis. Am J Psychiatry 1995; 152: 1705-1713.

77. Zhou X, Fragala MS, McElhaney JE \& Kuchel GA: Conceptual and methodological issues relevant to cytokine and inflammatory marker measurements in clinical research. Curr Opin Clin Nutr Metab Care 2010; 13:541-547
78. Zhou J, Nagarkatti P, Zhong Y, Ginsberg JP, Singh NP, Zhang $J$ et al.: Dysregulation in microRNA expression is associated with alterations in immune function in combat veterans with post-traumatic stress disorder. PLoS ONE 2014; 9: e94075.

79. Zhu CB, Blakely RD \& Hewlett WA: The proinflammatory cytokines interleukin-1beta and tumor necrosis factoralpha activate serotonin transporters. Neuropsychopharmacology 2006; 31:2121-2131.

Correspondence:

\section{Ms Bethan Dalton}

Department of Psychological Medicine, King's College London, PO59 Institute of Psychiatry, Psychology \& Neuroscience De Crespigny Park, London SE5 8AF, UK

E-mail: bethan.l.dalton@kcl.ac.uk 